\title{
Towards a National Policy on Suicide Prevention
}

\section{Dr Mrinmay Das}

Assistant Professor, Institute of Psychiatry, Kolkata

\section{INTRODUCTION}

Suicide is a global phenomenon and occurs throughout the life span. It is recognised as a critical public health issue by the World Health Organization (WHO) in its Comprehensive Mental Health Action Plan 2013-2020. ${ }^{1}$ In the year 2016, it was estimated that globally 817000 population committed suicide. This means world wide one person commits suicide in every 40 seconds.

Suicide deaths account for $1.5 \%$ of all death with global suicide death rate of 11.4 per 100000 population. Rate of women death due to suicide is 7 per 100000 and 15 per 100000 for men. It is the second leading cause of death among 15-29 year-olds globally. ${ }^{2}$ For every suicide, 25 people make a suicide attempt and many more have serious thoughts of suicide. Many millions of people worldwide are affected by suicide every year when the family members, friends, colleagues and communities of those who attempt suicide or die by suicide are taken into consideration. ${ }^{3,4}$

India has seen a steady increase in the incidence of suicidal deaths in the last five decades. The estimated suicide-related death rate in India is $21 / 100,000$, which is nearly twice the global average $(11.4 / 100,000) .{ }^{5}$ In 2016, there were 230314 suicide deaths in India. India's contribution to global suicide deaths increased from $25.3 \%$ in 1990 to $36.6 \%$ in 2016 among women, and from $18.7 \%$ to $24.3 \%$ among men. In India, men commit suicide 1.34 times frequently than women. In addition to all these worrying figures, another equally concerning global phenomenon is the changing demographics associated with suicide. There is a clear shift in the predominance of suicides from the elderly to the younger people all over the World and particularly in India. ${ }^{2,6,7}$. In 2016, suicide was the leading cause of death in India for those aged 15-39 years; $71.2 \%$ of the suicide deaths among women and $57.7 \%$ among men were in this age group. ${ }^{8,9}$ As this is the most productive age group, it has prolonged adverse future impact on country's socio-economic and demographic status.

\section{WHY INDIA NEEDS A NATIONAL SUICIDE PREVENTION POLICY?}

Considering the enormous global burden of suicide many international bodies have postulated programs time to time, either directly addressing suicide or incorporating and giving priority to this issue in other relevant programs.

In 1996, United Nations (UN) published the seminal document entitled "Prevention of suicide: guidelines for the formulation and implementation of national strategies" following consultation with a variety of experts and with technical support from WHO. Since the UN document was published, special attention and also knowledge about suicidal behaviour has increased greatly. WHO launched Mental Health Gap Action Programme (mhGAP) in 2008 , and suicide is one of the priority conditions of this programme.

Suicide mortality is also an indicator of target 3.4.2 for Sustainable Development Goal of United Nations, to be used to measure progress towards a targeted one third reduction in premature mortality from non-communicable diseases through enhanced prevention, treatment, and promotion of mental health and wellbeing by the year 2030. ${ }^{10}$

In the WHO Mental Health Action Plan 2013-2020, as a member state India is committed for working towards the global target of reducing the suicide rate in countries by $10 \%$ by 2020 . Till January, 2018, 
only 38 countries among 194 member states in WHO have national strategy for prevention of suicide; and India is not in the list. WHO has recognised India having very low quality of vital registration data on causes of death, including suicide. ${ }^{11}$

While India has marked pride presence in space and related sciences, by successfully launching Mars Orbiter Mission or Mangalayaan in 2013-14 and Chandrayaan-2 as lunar mission recently, the country is lagging behind in areas related to mental health, like, to formulate suicide prevention policy, which needs to be addressed urgently. Therefore, it is the need of the hour to make a national policy towards prevention of suicide in India.

\section{THE SIGNIFICANCE OF DEVELOPING A NATIONAL SUICIDE PREVENTION POLICY}

Any national policy acts as authoritative guidance for conducting nation-wide activities targeting specific goal. The importance of developing a national suicide prevention strategy has been comprehensively explored by WHO. The numerous benefits of national policy to prevent suicide include. ${ }^{12}$

- A national strategy not only outlines the scope and magnitude of the problem but, more crucially, recognizes that suicidal behaviour is a major public health problem.

- It signals the commitment of a government to addressing the issue.

- A policy recommends a structural framework, incorporating various aspects of suicide prevention.

- It identifies key stakeholders and allocates specific responsibilities to them. Moreover, it outlines the necessary coordination among these various groups.

- It also identifies crucial gaps in existing legislation, service provision and data collection.
- A policy indicates the human and financial resources required for interventions.

- It shapes advocacy, awareness-raising and media communications.

- A policy proposes a robust framework of monitoring and evaluation, thereby instilling a sense of accountability among those in charge of interventions.

- A strategy provides a context for a research agenda on suicidal behaviours.

\section{ROAD MAP FOR THE POLICY}

A country that decides to work on its national response to suicide prevention has an opportunity to tackle suicide prevention in a way that is meaningful to that country's context. Regardless of a country's current commitment to and resources for suicide prevention, the very process of establishing a national response can itself improve prevention.

In countries where suicide prevention activities have not yet taken place, the WHO recommends emphasis on action i.e. identifying stakeholders and developing activities where the need is greatest or where resources already exist.. In countries that have some existing suicide prevention activities, it may be productive to focus first on consolidation by conducting a situation analysis. ${ }^{11}$ India's position is somewhere between the above two scenarios. Therefore, it is important to take forward the current actions and move towards formulating a national policy to prevent suicide for achieving the ultimate goal of reducing the suicide burden. ${ }^{13}$

\section{A STRATEGIC APPROACH}

Formulation of suicide prevention policy at national level is much more complex than the act suicide. To tackle such a rapidly growing and multifaceted problem, no single strategy is likely to work best. Instead, a systematic, multipronged, collaborative prevention strategy that addresses population level as well as individual level factors, is essential. For this, a national suicide prevention strategy needs 
Towards a National Policy on Suicide Prevention

to be multi-sectoral, involving not only the health sector but also other sectors such as education, labour, social welfare, agriculture, business, justice, law, defence, politics and the media. The strategy should be tailored to India's cultural and social context. When conceptualizing and implementing a national suicide prevention strategy through an action plan, it is necessary to specify clear objectives, targets, indicators, timelines, milestones, designated responsibilities and budget allocations. The following elements are key to the success and sustainability of the national strategy. ${ }^{12}$

\section{- Identify stakeholders :}

For a successful national policy to prevent suicide in line with World Health Organization recommendations, will require strong commitment and effective liaison among all stakeholders. Therefore, it is important to identify the key stakeholders in suicide prevention when developing a national strategy. Suicide prevention needs to involve different actors and disciplines working on suicide prevention - such as different ministries, health administrations, non-governmental and nonprofit organizations, universities and civil society, religious and spiritual organizations, community, family as well as the individual. ${ }^{11}$

\section{- Undertake a situation analysis :}

A thorough situation analysis, starting with the data available, identifies the extent of the problem in a particular geographical area (whether an entire country or a specific subregion of a country). The identification of barriers an important part of the situation analysis.

\section{- Assess resources :}

The availability of and access to both human and financial resources, for both development and implementation, are central to the success of any public health intervention.

\section{- Achieve political commitment}

Political commitment is essential for ensuring that suicide prevention receives the resources and attention that it requires from national, state and local leaders. Achieving political commitment that is sustainable and which transcends changes in the government is a long and challenging process.

\section{- Address stigma}

Stigma related to suicide remains a major obstacle to suicide prevention efforts. Those who are left behind or who have attempted suicide often face considerable stigma within their communities, which may prevent them from seeking help. India has taken a very important step in this regard in the Mental Health Care Act, 2017 by decriminalizing the act of suicide. It is also possible that decriminalization will increase the reporting of suicides once fear of legal recriminations is eliminated which will subsequently give more accurate estimates of the true extent of the issue. ${ }^{11}$

\section{- Increase awareness}

For an intervention to be successful, public requires an understanding of the issue and the need for intervention. The process of developing a suicide prevention policy offers opportunities to increase awareness about suicide. Awareness efforts can also generate greater and more sustained involvement from stakeholders and buy-in from communities that recognize the importance of suicide prevention.

\section{- State clear objectives}

An effective suicide prevention strategy should have several parallel and interconnected objectives that need to be stated clearly.

\section{- Identify risk and protective factors}

The identification of relevant risk and protective factors at individual, family, community and societal level for both suicide and suicide attempts can help to determine the nature and type of interventions required. Suicide behaviour is a multifaceted problem with complex interaction of biological, social, psychological and environmental risk and protective factors. Gajalakshmi et al appropriately described this behaviour as a complex array of socio-cultural-economic factors. ${ }^{14}$ There are also the protective factors that work at different levels- 
community, family and individual level which support someone with intrusive suicidal thoughts, or mitigate some of the other risks - these too need to be identified.

\section{- Select effective interventions}

Based on relevant risk and protective factors, as well as the situation analysis and resources allocated, a national strategy and its action plan for implementation can propose the most suitable type and combination of effective evidence-based interventions - universal, selective and indicated. Combining the above interventions, Menon, et al. ${ }^{15}$ proposed a multitier approach to suicide prevention. This framework combines: population level - universal prevention (Tier 1 - awareness program and media strategies), subpopulation levelselective prevention (Tier 2 - screening, gate keeper training, help line or hotline), and individual-level (Tier 3 - follow up care, pharmacotherapy and psychotherapy) strategies. As one progresses from Tier 1 to tier 3 , the strategies become more proximal and individually focused. This framework may help in designing a comprehensive approach to suicide prevention with adequate focus at the population as well as individual levels.

\section{- Improve case registration and conduct research}

Surveillance systems are needed to improve the availability and quality of data as suicide often remains misclassified, unreported or under-reported. Suicide attempt data are as a prior suicide attempt is the strongest predictor of subsequent suicide in the general population. A systematic approach for gathering data in a sustained manner is very essential. Research is important for understanding the risk and protective factors and vulnerable persons for a given context.

\section{- Conduct monitoring and evaluation}

Monitoring and evaluation need to be planned and agreed upon in advance to ensure the involvement of all relevant stakeholders, including inputs from key personnel involved in the implementation of interventions as well as feedback from community members. Evaluations are important for indicating whether changes need to be made to an intervention or whether it can be scaled up. While evaluating the strategy as a whole, the evaluation of individual interventions that are being implemented offers opportunities to examine critically the outcome and impact of these interventions in terms of the stated objectives. Monitoring and evaluation should be seen as part of a continuous feedback loop that is designed to allow refinements to be made to improve the strategy as it progresses.

\section{AN OVERVIEW OF INTERVENTION TECHNIQUES AND THEIR KEY ELEMENTS :}

Menon et al..$^{15}$ in their recent review article identified eight groups of suicide prevention strategies and their key elements. The strategies as following : education and awareness programs, screening programs, gatekeeper training, restricting access to means, media strategies, telephonic hotlines, therapeutic approaches, and follow-up care.

In education and awareness programs following are the key elements : Dissemination of educational information through multiple methods such as media, short talks, leaflets, and placards. Sharing of survivor experiences; combining awareness with screening programs; educating primary care providers to recognize and respond to psychological distress.

Following effective components in screening have been identified : using screening tools with good sensitivity, specificity, and incorporating screening approaches in emergency department and primary care evaluations.

Training gatekeepers (e.g. teachers, primary care physicians, medical nursing personnel in the emergency and casualty departments, staff of correctional facilities, traditional healers, priests, etc.) to recognize the early warning signs of suicide, how to approach and talk about the very 
confidential and sensitive issue, psychological first aid, and basic postvention activities; knowledge of at-risk populations and referral strategies and in its management will help inprevention.

Guideline for media practices are as follows : Avoid sensationalizing and explicit description of suicide methods, emphasize preventability of suicide and treat ability of predisposing mental health conditions, and provide contact details for suicide support services, collaboration between media and medical professionals and training of journalists on responsible reporting.

There are various modes of restriction of means to suicide. The important practice elements are legislative restrictions on availability and sale of firearms/pesticides, constructing physical barriers at jumping hotspots, use of drugs safer in overdose. A phenomenon arising due to means restriction is "means substitution" wherein the individual may simply substitute one suicide method with another. ${ }^{16}$

Suicide re-attempt rate is highest in the first week following discharge from hospital and it may last up to 3 years. If in this period the person remains in follow up care the risk for re-attempt is reduced. Follow-up measures may be in different forms, likecaring letters, postcards, frequent phone calls, text messaging, brief and regular sessions of supportive counseling, follow-up by mental health worker, and community outreach programs. ${ }^{17}$

Suicide prevention hotlines or help lines provide phone-based services for individuals who are at risk of suicide or concerned about someone at risk of suicide. There are evidences that suicide prevention hotlines either telephonic or internet based has impact on suicide risk reduction though there is dearth of literature on this topic. ${ }^{18}$ This is now established that different the rapeutic modalities such as antidepressants, lithium, clozapine, ketamine, electro convulsive therapy, different forms of psychotherapy have important role in reducing suicidal ideas.
The suicide prevention interventions also work in line with general principal of level of prevention. It can be conceptualized that components of primary suicide prevention intervention as awareness programs, access to means restriction, skill based enhancement. Secondary suicide prevention strategies comprised of screening, gatekeeper training and improving reporting by media or media education. Lastly tertiary suicide prevention strategies are crisis interventions in the form of treatment by means of pharmacotherapy and/or psychotherapy, hotlines or helplines, follow-up care. ${ }^{19}$

Besides all those prevention strategies, while formulating a national policy for suicide prevention for India, the mind fullness based stress reduction techniques should also be emphasised at different levels. This may be considered as method of primordial prevention of suicide. Inclusion of such techniques in daily life can go a long way in not only by preventing the risk of suicidal behaviour, but also in promotion of a healthier and purposeful living for all. Mindfulness stress reduction techniques have been found to reduce stress and suicidal behaviour across various population groups. ${ }^{20,21}$ Such programmes are already functioning in different areas in India by different agencies. Govt. of Maharastra has initiated a programme named 'MITRAUpakram' (Mind In Training for Right Awareness) in 2011. Under this programme Government school teachers are taught Vipasana and school going children are taught Anapana meditation. It is found that the measure to be of good use in cultivating interest among students for their curricula, improving their overall performance and reducing undesired behaviour. Another ongoing programme is a worth of mentioning All India Council of Technical Education (AICTE) has initiated a 3 week induction programme for its fresher graduates. The course was approved for all engineering colleges by AICTE in March, 2017. This is based on universal moral values and aims for stress reduction amongst the youth. The purpose of this program is to help new students adjust and feel comfortable in the new environment, inculcate 


\section{Towards a National Policy on Suicide Prevention}

in them the ethos and culture of the institution, help them build bonds with other students and faculty members, and understanding of the self, people around them, society at large, and the nature and expose them to a sense of larger purpose and selfexploration.

\section{CONCLUSION}

The suicide rate in India is about double as compared to global rate. A further worrying fact, the rate is much more in the most productive age group, which has an adverse impact on future socio economic and demographic profile of India. There are de-synchronised, scattered services available at different level of various parts of India. Those services are not comprehensive to meet the purpose to reduce suicide death throughout the country, uniformly. Therefore, India urgently needs a national suicide prevention policy which can be adopted by the guiding principles of WHO which are evidence based strategies and also incorporating the basic Indian cultural essence of spiritualism based mindfulness techniques.

\section{REFERENCES}

1. World Health Organization. Comprehensive mental health action plan 2013-2020. World Health Organization, 2013.

2. Dandona R, Kumar GA, Dhaliwal RS, Naghavi M, Vos T, Shukla DK, et al. Gender differentials and state variations in suicide deaths in India : The Global Burden of Disease Study 1990-2016. Lancet Public Health; 2018. Available from : https://www.linkinghub.elsevier.com/retrieve/ pii/ S2468266718301385.

3. Working Together to Prevent Suicide. Brochure on World suicide prevention day from International association for suicide prevention, 2018. Available from : URL: https:// iasp.info/wspd2018/.

4. Pitman A, Osborn D, King M, Erlangsen A (2014). Effects of suicide bereavement on mental health and suicide risk. Lancet Psychiatry. 1(1) : 86-94.

5. Ministry of Home Affairs, Government of India. National Crime Records Bureau. Accidental Deaths and Suicides in India. New Delhi. Available from : http://www.ncrb.gov. in/StatPublications / ADSI/PrevPublications.htm.

6. Kyu HH, Pinho C, Wagner JA, Brown JC, Bertozzi-Villa A, et al. Global and national burden of diseases and injuries among children and adolescents between 1990 and 2013 :
Findings from the Global Burden of Disease 2013 study. JAMA Pediatr 2016; $170: 267-87$.

7. Patel V, Ramasundarahettige C, Vijayakumar L, Thakur JS, Gajalakshmi V, Gururaj G, et al. Suicide mortality in India : A nationally representative survey. Lancet 2012; 379 : 2343-51.

8. Institute for Health Metrics and Evaluation. GBD compare data visualization. https://vizhub.healthdata.org/gbdcompare/.

9. Office of the Registrar General of India, Ministry of Home Affairs, Government of India. 2011 Census data : C-13 single year age returns by residence and sex. 2011. http://www. censusindia.gov. in/2011census/C-series/C-13.html

10. United Nations. The Sustainable Development Goals Report. United Nations, 2017.

11. World Health Organization. Preventing suicide: a global imperative. Geneva, Switzerland : World Health Organization, 2014 http://www.who.int/mental_health/ suicide-prevention/en/

12. WHO (2012). Public health action for the prevention of suicide : a framework. Geneva : World Health Organization, 2012.

13. Nebhinani N, Singhai K Suicide prevention strategies for adolescents and youth : Where are we missing? J. Indian Assoc. Child Adolesc. Ment. Health 2019; 15(2) : 1-12

14. Gajalakshmi V, Peto R. Suicide rates inrural Tamil Nadu, south India : Verbal autopsy of 39000 deaths in 1997-98. Int J Epidemiol. 2007; 36 : 203-7.

15. Menon V, Subramanian K, Selvakumar N, Kattimani S Suicide prevention strategies : An overview of current evidence and best practice elements. Int J Adv Med Health Res $2018 ; 5: 43-51$.

16. Yip PS, Caine E, Yousuf $\mathrm{S}$, Chang SS, Wu KC, Chen YY Means restriction for suicide prevention. Lancet 2012; 379: 2393-9.

17. Ghanbari B, Malakouti SK, Nojomi M, Alavi K, Khaleghparast $\mathrm{S}$. Suicide prevention and follow-up services : A narrative review. Glob J Health Sci 2015; 8: 145-53.

18. California Department of Mental Health, Office of Suicide Prevention. California Suicide Prevention Hotline Survey Report. Sacramento, California; 2011. Available from: http: / / www.dhcs.ca.gov/services / MH/Documents / Hotline Survey Report.

19. Waldvogel JL, Rueter M, Oberg CN. Adolescent suicide: risk factors and prevention strategies. Current problems in pediatric and adolescent health care. 2008, $4: 110-25$. (Online available figures)

20. Sharma E. Mindfulness based interventions for children. J. Indian Assoc. Child Adolesc Ment Health 2014, 10 : 1-8

21. Pradhan S, VV AK, Manju S. Effect of Vipassana meditation on mindfulness and life satisfaction of employees. International Journal of Research in Commerce \& Management 2016, $7:$ 11-16. 